\title{
Culture, Sexuality and Indigenous Healing in Pakistan: Exploring Sexual Health Care through Hakeems and Herbalists
}

Abdul Qadar ${ }^{1}$, Hakeem Zia Ur Rehman ${ }^{2}$

\begin{abstract}
Objective: This paper aims to understand the relationship between sexuality, culture, and male sexual health through the role of hakeems as an indigenous healing framework in Pakistan.

Study Design: Participant observation (by first author) and personal practice (by second author).

Place and Duration of Study: At a matab where second author practices hikmat is located in Islamabad. The fieldwork in the form of collaborative learning has been going on since September 2019 to date.

Materials and Methods: This research is based on the participant observation at the matab where people come to seek herbal medicine and consultancy from the hakeem. Narrative account of anthropologist and practice of certified hakeem, through an interactive exchange of ideas about questions of the study, was employed. The study has taken information in the form of semi-structured interviews from the patients who either gave consent or asked to remain anonymous.

Results: Results have shown that the nature of the relation between sexuality and cultural order have compelled people to seek hikmat as indigenous healing on a long-term basis. The framework of indigenous healers has helped to understand the cultural logic of sexuality, which is embedded more closely in the practice of hakeems than the biomedical regime.

Conclusion: Cultural competence, in this case the same cultural background of the hakeem and patients, adds to our understanding of the indigenous healing framework, sexuality, and culture.
\end{abstract}

Key Words: Culture, Hikmat, Indigenous Healing, Manliness, Sexuality.

How to cite this: Qadar A, Rehman HZ. Culture, Sexuality and Indigenous Healing in Pakistan: Exploring Sexual Health Care through Hakeems and Herbalists. Life and Science. 2020; 1(4): 149-155. doi: http://doi.org/10.37185/LnS.1.1.113

This is an Open Access article distributed under the terms of the Creative Commons Attribution License (http://creativecommons.org/licenses/by/4.0), which permits unrestricted use, distribution, and reproduction in any medium, provided the original work is properly cited.

\section{Introduction}

Understanding sexuality as a lived and expressed experience is of profound importance to explore the relationship between individual healing and culture in Pakistan. The case of sexual health is particularly interesting in this regard when, despite the social and biological salience of sexual health, its status remains of a taboo topic in all forms of parlance in the society. This paper focuses on the potentialities

${ }^{1}$ Department of Social and Behavioral Sciences

National University of Medical Sciences, Rawalpindi

${ }^{2}$ Kashmir Pansar and Herbal Medicine Store

Sector G-9, Islamabad

Correspondence:

Dr. Abdul Qadar

Assistant Professor, Social and Behavioral Sciences

National University of Medical Sciences, Rawalpindi

E-mail:abdul.qadar@numspak.edu.pk

Funding Source: NIL; Conflict of Interest: NIL

Received: Apr 19, 2020; Revised: Aug 19, 2020

Accepted: Sep 14, 2020

149 of male sexuality, its understanding in indigenous healing by hakeems (a physician who deals with indigenous health issues and their treatment) and the herbalists (locally known as pansar) against the otherwise biomedical system of health care in the country. One important addition to the understanding of the health system of Pakistan pertains to the role of herbalists and hakeems as indigenous healers besides chiropractors, pirs (spiritual leader to whom people pay allegiance for their spiritual guidance), and imams (prayer leader) as every day religious healers.

This study does not take in its fold the healing potential of spiritual and religious leaders besides quacks who lack formal training in either knowledge of biomedical or hikmat. In this study, treatment of sexual health-related problems, perceptions, communication with the healer, and the role of healer are the prime focus. This choice of the 
indigenous healing framework is borrowed from Kleinman and Sung (1979), who observe that "crosscultural and historical studies of medicine disclose two separate, but interrelated healing functions: control of sickness and provision of meaning for the individual's experience of it". ${ }^{1}$ This one aspect of sexuality as a cultural construction and its role in healing is of fundamental importance when we think of indigenous healers and sexuality as localized socio-biological conditioning of the affected individual. The reason to treat sexuality as a cultural construction is also grounded in the fact that despite the taboo status of sex, it is also one of the most widely talked and advertised topics in Pakistan. The scope of its advertisement incorporates almost all forms of media, i.e., print, electronic and social, along with wall chalking, pamphlets, posters, etc.

Taking indigenous healing as radically differentiated from the biomedical knowledge regime, which arrogates the right to treat only to the regime itself, we find it important to know how certain possibilities to speak for knowledge about health and healing are structured. It reminds us about the medical profession's reluctance "to give up their hegemony of sexual knowledge" and how it regulates "who could speak, when they could speak, and how they could speak". ${ }^{2}$ Foucault has taken this epistemic politicization further to see how biomedical knowledge shapes and defines "the techniques of power exercised over sex, having not obeyed a principle of rigorous selection, but rather one of dissemination and implantation of polymorphous sexualities". ${ }^{3}$ Similar concerns are also traced as universal patterns with differing intensities as Kimmel and Plante pertinently remind us that "more universal the sexual behavior is, the more secretive and private we are about it". ${ }^{4}$ Given this introductory background of cultural sexuality, its operative frame of indigenous healing, and the settings of the fragile health system in Pakistan, we aim to explore the relationship between culture, sexuality, and articulation of health as an individual in Pakistan.

\section{Materials and Methods}

Methodologically, the paper reflects on an anthropologist's participant observation (ongoing since September 2019) at a matab in Islamabad, where the second author who practices hikmat at the matab, have collaborated to ground the research questions. There have been important ethical considerations while conducting research. Due to the nature of research and the possibility of compromising people's private lives, data was collected anonymously sharing sensitivities of the concerned people.

The ethics and research methodology were kept in close harmony; however, we are of the view that the relationship between culture, sexuality, and healing can only be explored by taking people's sexual lifeworlds beyond sensual pleasure, potency, and manliness. Similarly, Maurice Godelier rightly reminds us that sexuality as a topic of research should "lead the anthropologist to extend his or her observations to all of the social relations" and going beyond purely sexual relations to "relationships with power, with wealth, within the material division of labor, in their rites, and so on". Similarly, our methodological layout of the study has opened the possibilities for us to dig deeper into the broader picture of the socio-cultural construction of male sexuality and the role of indigenous healing as a health system in Pakistan. We have also aimed to give the people who visit matab their space as conscious subjects because "part of the engagement with patients' cultural influences means acceptance of their worldview as it pertains to their health concerns". ${ }^{6}$ Thus, this study is embedded in a consciousness where sexuality and indigenous healing are operationalized in culturally nuanced ways.

We both find it important to refer to our position in this study because the practice of sexual research is itself grounded in the position of the researcher in such a way, as Javaid shared his experiences, "a social and cultural process, shaped by social relations and social structures". ' Here, we find our research interests to be mainly driven by the larger settings of the roles and institutional structures of Pakistani society where "theories about disease and its causes are translated into treatment as part of a wider social structure which results in a distinctive medical practice ${ }^{\prime \prime}{ }^{8}$ Therefore, we extend our analytical optics to the social structure in Pakistan and its relation with healing practices, which are embedded in sexuality as an articulation of a male's self.

How is Sexuality an Embedded Holistic View of self in Pakistan? 
Fieldwork for this study has often reminded us of limited understanding about sexuality in the early days of collaborative fieldwork at the matab. For example, when one of the neighboring store Incharge (as he introduced himself) came to visit the matab and asked if we wanted to listen to his account. We readily offered him a chair turning attentively to him so that he could sit and share his thoughts. The person in his 30s asked the first author (calling Dr. sahib) if he knew that sexuality is more about psychology and then about the mazhabi (religious) and ikhlaaqi (moral) conduct of someone. He narrated his experience through his distance from his wife, who lives almost 300 kilometers away from his working place. He was of the view that he only feels himself bhra hua (filled with sexual urge) when he is with his wife. Otherwise, he does not exhaust himself sexually while working in Islamabad. His meanings of sexual intercourse were representatives of what he earlier mentioned as the mental, religious, and moral sum of the sexual activity. Interestingly, as the person left the store, one of the staff members who was listening to his account shared that this man comes at the store only to seek his potency for his kept (a female sexual partner in exchange for monetary patronage) in Islamabad. For our discussion, both accounts told us that some people could be very open about their sexuality, and most people are judgmental in their opinions about other people when it comes to sexuality. This one event and many others in their particular characteristics have proved to help determine the relationship of sexuality as an exclusive topic in discussions about health, culture, and society.

Therefore, we argue that sexuality is socialized in Pakistan in a very particular way to knit religiocultural, medical, and social tenets of its discursive, lived, and idealized formations. Therefore, one finds a compelling case to explore construction of the self of an individual in these settings of identity when sexual health acts as the strong defining factor. We have discussed sexuality from the fieldwork carried out at the matab and pansar store as socio-medically communicated, psychologically enacted, and ideally reached a point which is considered as the culmination of the capability as a complete male. Furthermore, these aspects of self as constituted in the achievement of a certain level of sexual health, which is mostly referred to as taaqat (sexual potency) is used in male idioms or at least known to us due to the limited scale of our research (women are not part of the study). These references to maleness are further coupled with socially recognized jargons related to family and progeny (referring to wife and kids as the rightful receptor and reasons for sexual activity) and mardaangi (maleness as an attribute of a socially strong and sexually vigorous male individual). Though womanhood is also closely connected with the potential to become mother, yet it is differently related to the sexuality of women, who are socially expected as modest, passive, and moderate in their expressions of sexuality.

To focus more closely on the importance of sexuality, one can find notions of good and bad men resulting from their sexual practices in defining the manliness with its defined attributes. For example, there is a grave concern for both parties, either hakeem or patient, to keep religious and moral uprightness intact while seeking sexual vigor. This aspect is also repeatedly discussed at the matab and in the pamphlets and advertisements on public spaces when sexuality is encouraged only for the aulad (progeny) and satisfaction of the wife. This is also recalled by the second author that whenever the hakeem himself or his staff know that the person who is asking for male potency enhancing nuskha (prescription), is using his vigor with an illegitimate partner, then there is no barkat (blessing) from God in the form of shifa (healing). As a case in point, the senior hakeem sahib (father and trainer of the second author) also does not allow the practice of such prescriptions. However, this is not possible for the matab staff to ensure that every person who is seeking help is using his vigor with a legitimate partner. Still, the staff believes that this ensures the barkat of Allah in the form of shifa e kamla (complete healing). This religious tone of medication is again rooted in otherwise profuse Islamization of locally manufactured herbal medicine. As a case in point, one can see that most of the pamphlets and brochures use Quranic ayats (verses) and names of God to seek His blessings. Similarly, people also share at the matab about this religious tenor to be highly effective because they believe that there is nothing to heal more powerfully than the will of God. This 
provides us with the opportunity to locate the simultaneous presence of sexuality as a taboo topic and its flowing power from God as the ultimate source of all kinds of power, health, and blessings.

This also takes us back to what one of the clients mentioned as psychological, religious, and moral overtones of the sexual activity. Like the above-given discussion, which highlights the role of religious symbolism and beliefs in the healing potential of medicine (locally referred to as khurak, which can be translated in English as food or dose), there is also use of moral and psychological factors in this regard. For example, the staff at matab believes that all three components work together when a person talks about his sexual urge limited to his wife. It carries religious significance because religious references are quoted when they refer to Godly pleasure upon wife and husband's legitimate sexual act. Similarly, it is believed that the act of sex with wife is socially endorsed and leads to the moral standing of both the husband and wife as keeping themselves pure for each other. On the other hand, contestation of the referred person's narration also symbolized this otherwise ideal conduct of sexual purity. The psychological component comes from the tranquil and calm environment when the wife and husband have conducive private time for their sexual arousal and the resultant satisfying intercourse. This is an important reminder of the social construction of sexuality when cultural notions of morality, religious uprightness, and psychological effectiveness all come together in Pakistan to define successful maleness.

\section{How is Indigenous Healing Inclusive and Informed?}

We take this holistic understanding of sexuality to its relationship with the indigenous healing framework and role of hakeems. It is common to notice that a visit to the matab is usually not every time for checkup and treatment. Instead, a visit to the matab varies from advice about someone ill in family, friends, and neighbors to the counter-checks against medical doctor's prescriptions. For example, this is also a very important aspect of the matab routine that some overlapping expressions are used for the visitors, i.e., customer, client, or patient. This count of entitlement for any specific phrase has equally blurred one for the matab staff because one person coming for a particular item turns out to be a patient when he/she is suggested different relevant medicine and prescription. Similarly, one patient who comes only to ask for some specific herbal medicine becomes a customer when suggested an original herb instead of prepared medicine. In this background, one can find the notions of mutual interaction in a more rooted way. The trust about the mutual relationship is vital for both the hakeem and the patient because, according to the experiences of the second author, people do not act only as passive patients when they seek medical help. Male customer-turned-patients who come to seek different prescriptions and develop a rapport with the hakeem are more likely to feel that now they are in a better position to ask for the sexual potency enhancing organic supplements (called mardana taaqat $k$ nuskhay). These feelings of rapport also ensure that those who consume such medicine are also least vulnerable to the disrepute of sexual impotence, which is one of the most serious stigmas for any male in the society. According to second author, one has to keep in mind financial position of the people who visit, and this compels to accept the bargained amount also. He is often asked by different customers cum patients to reduce the bill because they are his regular customers. This nature of the relationship, which goes beyond treatment or medication, sometimes results in zero profit from some patients. For example, a man known to him as his uncle (due to closeness with his father) asked him to prepare the medicine for him, who then went to offer his Hajj at Prime Ministerial quota without paying him. According to second author and some of his customers who seek only sexual potency enhancement, this shared concern is the most important marker of the hikmat and sexuality.

We both agree that this personalized notion of relationship, which results in confidence and secrecy, is the building block of this indigenous health framework separating hikmat from biomedical knowledge and its practice. Most of the people identify that a significant lacuna with biomedical knowledge and practices of sexuality is its rootedness in over-medicalization of health in general and then placing sexuality also in its eroticism, i.e., timing pills, etc. in particular. Wiederman familiarly argues about overmedicalization for "Erectile Dysfunction (ED) 
treatments have both captured the popular imagination, and been critiqued as an overmedicalization of a complexly bio-social experience". ${ }^{9}$ On the other hand, there are possibilities and practices of the approaches towards sexuality and sexual organs in line with what Margaret Lock refers to the portrayal of the body beyond its place as a "template for social organization" or as a "biological black box cut off from mind and nature/culture and mind/body dualities are self-consciously interrogated". ${ }^{10}$ We concur that it is one of the core elements of any medical system to serve its purposes optimally to be inclusive and open to accept the needy ones as equally capable people. Unless one realizes that medical care is the framework of holistic, moral, religious, social, and cultural settings, one cannot completely understand it. For example, the ethnography of our study is inclusive of the people's fears, fantasies, and construction of their sexual potential, which is in line with the larger cosmos of societal normative sexual conduct. It is ubiquitous for males to feel their frightening moments when the time of marriage comes closer. Most of the people would give accounts of their friends' tales about challenging potency required during sexual intercourse. People would share that it is legitimate because this leads to religiously prescribed sexual intercourse and becomes necessary because the male is believed to overpower a woman with his sexual potency.

For most people, the efficacy of the medicine they receive from matab is in the localization of the whole process, be it ingredients of the medication, its preparation, the language of the hakeem, and, above all, the possibility to self-tailoring of the medicine. According to the second author's opinion as a practitioner, the marriage courses, referred to the nuskhas are aimed to consider holistic acceptance of the body and the medicine in the language of the people's beliefs. For example, people are cautious about the usage of nuskhas and how they relate the use of these nuskhas with what they refer to as garmi (heat) not only of sexual organs but of complete bodies. Hakeem's understanding of the patient's need is broad enough to consider how the sociocultural construction of sexuality is framed within a larger socio-cultural construction of human bodies.
For example, most people come to the matab when their marriage date has been fixed, and the belief to conquer a woman's body is deemed essential for the successful, lasting impact of manliness. This is a widespread concern for most of the visitors at the matab that first-night sexual intercourse leaves an everlasting imprint of the man on his wife. Thus, people who have fears and fantasies of the sexual act beyond the pleasure, demand the hakeem to prepare the nuskha keeping all this background in view. Furthermore, it is also closely connected to morality as another significant character of hakeem's role in the articulation of the relationship between hakeem, patient, and moral cosmos. There is a complete code of moral notions that decide for the constitution of allowed and disallowed sexuality in its exercise. For example, it is believed that either people come for the marriage course or they come to seek help for offspring. What comes out of these only options is also the fact that both notions serve the purpose of the morally rightful act of having potency for sexual intercourse. It is very common for the people to resort to their moralistic language and coded expressions at the matab while talking about their sexual needs.

\section{Discussion}

This paper has tried to address some of the crucial questions which are not limited only to the key research areas of the paper like sexuality, culture, and indigenous healing. It also highlights "individuals are developing and refining their interpersonal and intrapsychic sexual scripts". ${ }^{11}$ Similarly, Zilbergeld is also closely relevant here when he argues that "the sexual messages conveyed in our culture are the stuff of fantasy, of overheated imaginations run wild, and that's why I call them collectively the fantasy model of sex". ${ }^{12}$ Therefore, to better explore the direct and indirect inroads of sexuality, we have treated the subject of sex "in its institutional setting, and through its manifestations in other aspects of culture" because we think as Malinowski opines about love, sexual approaches, eroticism, combined with love-magic and the mythology of love as part of the complete lifeworld of Trobriands. ${ }^{13}$ We have also tried to think about the representations of both the imagined and real version of sexuality, suggesting one core element of sexuality: the completeness of human being as an 
optimally capable sexual individual. This also incorporates sexuality as an integral social and medical condition of manliness grounding sexuality both as a culturally coded model of health and healing where biomedicine is presented as limited and lacking in issues surrounding the questions of sexuality.

While looking for the role of hakeems as an indigenous framework of healing, we agree with Kleinman and Sung as they point out that "there seems to be a radical discontinuity between contemporary clinical care and traditional forms of healing" ${ }^{11}$ which is also visible when we see sexuality as it is practiced in bio-medical health. Therefore, hikmat, as an indigenous framework, emerges more holistic than the exclusive biomedical practice because of the very operative nature of both the systems. What we call as holistic nature of the indigenous healing framework is rooted in the reason that it explores sexuality, which serves as the cornerstone of completeness of self in the social order of society. It is true that the same is also an important aspect of biomedical care, but what distinguishes it from the hikmat is the essence of long-lasting effects coupled with everyday relevance of the whole working procedure. These shared meanings of sexuality are rooted in the socio-cultural landscape of the sexuality in the first place and then its recourse to indigenous healing as the health care mechanism in this regard.

We have tried to locate our understanding of sexuality in its apparent ambiguity as one of the most important defining markers of essential characteristics of male individuality and, on the other hand, of taboo status. This salience also lies in the fact that all the conversations about sexual acts, sexual organs, and the word sex are cloaked in such a mystery that there is no other word so "freighted with developmental and health implications as the word sex" ${ }^{14}$ Similarly, this mystery around the notion of sex goes beyond the act to whole logic more as cultural conduct than the health issue at the matab of the fieldwork. As a case in point, the discussion between senior hakeem sahib and his son, who is also his trainee, remains very coded and secretive to the best possible scenario. The discussion would remain limited only to symptoms of illnesses (using appropriate words according to the second author) and their treatment, but keeping in mind that a father is talking to his son, who happens to be the shagird (trainee) hakeem. Apart from what is necessary to talk at matab, there is hardly any possibility for the father and the son to have a conversation about sex and sexuality. Likewise, beyond matab, we are convinced that despite secrecy behind sex, it does have its social importance required for the articulation of complete male personhood. This link between secrecy on the one hand and widespread concern, on the other hand, is the essence of research questions which try to explore cultural sexuality and indigenous healing system. Therefore, we concur in this regard that the "meanings a person gives to his or her sexual practices" serve as the most "intimate links to the values of a particular society and reveal the complex nexus between individual experience and community norms". ${ }^{15}$

\section{Conclusion}

This paper has discussed in detail about the importance of the relationship between culture, sexuality, and health in Pakistan due to the strong link between all three factors. Sexuality, as a fantasy and lived experience, is framed within the discussions of cultural limits and indigenous healing. Therefore, the notion of indigenous healing embodies medical supplements, the role of religious beliefs, notions of legitimate and illegitimate, and morally acceptable conduct of the sexual act.

\section{REFERENCES}

1. Kleinman A, Sung LH. Why do indigenous practitioners successfully heal? Soc Sci \& Med. 1979; 13: 7-26.

2. Weeks J. Sex, Politics and Society: The Regulation of Sexuality Since 1800. 3rd edition. London ; New York: Routledge; 2014.

3. Foucault M. We "other Victorians." In: Rabinow P, editor. The Foucault Reader. Harmondsworth: Peregrine; 1986; p: 292-300.

4. Kimmel MS, Plante RF. Introduction to Sexualities. In: Kimmel MS, Plante RF, editors. Sexualities: Identities, Behaviors and Society. New York: Oxford University Press; 2004. p. xi-xvi.

5. Godelier M. What is a sexual act? Anthropological Theory. 2003; 3: 179-98.

6. Winkelman M. Culture and Health: Applying Medical Anthropology. San Francisco: Jossey-Bass; 2009.

7. Javaid A. Reconciling an irreconcilable past: Sexuality, autoethnography, and reflecting on the stigmatization of the 'unspoken.' Sexualities. 2019; p: 1-29. 
8. Lyon W. Competing Doctors, Unequal Patients: Stratified Medicine in Lahore. In: Donnan $\mathrm{H}$, Werbner $\mathrm{P}$, editors. Economy and Culture in Pakistan: Migrants and Cities in a Muslim Society. New York: Palgrave Macmillan. 1991; p: 143-62.

9. Wentzell E, Inhorn MC. Maculitites: The Male Reproductive Body. In: Mascia-Lees FE, editor. A Companion to the Anthropology of the Body and Embodiment. West Sussex: Wiley-Blackwell; 2011; p: 307-19.

10. Lock M. Cultivating the Body: Anthropology and Epistemologies of Bodily Practice and Knowledge. Annu Rev Anthropol. 1993; 22: 133-55.

11. Wiederman MW. Sexual Script Theory: Past, Present, and Future. In: DeLameter J, Plante RF, editors. Handbook of the Sociology of Sexualities. New York: Springer; 2015.

12. Zilbergeld, Bernie. 1999. The New Male Sexuality, Revised
Edition. Revised, Subsequent edition. New York: Bantam.

13. Malinowski B. The Sexual Life of Savages: In North-Western Melanesia. $3^{\text {rd }}$ edition. London: George Routledge and Sons; 1932.

14. Sutton MJ, Brown JD, Wilson KM, Klein JD. Shaking the Tree of Knowledge for Forbidden Fruit: Where Adolescents Learn About Sexuality and Contraception. In: Brown JD, Steele JR, Walsh-Childers K, editors. Sexual Teens, Sexual Media: Investigating Media's Influence on Adolescent Sexuality. Mahwah, New Jersy: Lawrence Erlbaum Associates; 2002; p: 25-58.

15. Amuchástegui A. Researcher Bias in the Field of Sexuality and Reproductive Health. In: Zeidenstein S, Moore K, editors. Learning about Sexuality: A Practical Beginning. New York: The Population Council, Inc. 1996; p: 86-97. 